\title{
The influence of agricultural practices in vineyards on the predisposition of wines to crystalline turbidities
}

\author{
Anton Khrapov*, Anton Prakh, and Mikhail Antonenko \\ Federal State Budget Scientific Institution «North Caucasian Federal Scientific Center of \\ Horticulture, Viticulture, Wine-making», 39 str. 40 Let Pobedy, Krasnodar, 350901, Russia
}

\begin{abstract}
On the example of the Cabernet-Sauvignon variety, the dependence of the physicochemical parameters of grape must and the wine materials produced from it, on the formation of the grape bush (Cordon or Guyot) and green operations (chasing the upper leaves, pinching, removing stepsons) is shown. The influence of the listed factors on the predisposition of wines to crystalline turbidities is shown.
\end{abstract}

\section{Introduction}

The problem of giving the wine stability throughout the entire guaranteed shelf life is still relevant for both large and small wineries. One of the main reasons for the violation of the wines stability is the formation of crystalline turbidity (in different years, up to $70 \%$ of finished wines are prone to the formation of crystalline precipitates [1, 2]).

Various technological equipment and auxiliary materials can be used to combat crystalline turbidities [3-11], however, most of the methods for stabilizing wines to crystalline turbidities are extremely expensive and / or energy-intensive, as a result of which many enterprises, especially small farms, simply can not afford to use them.

It is known that most of the physicochemical indicators of the wine quality are formed at the stage of growth of the grape plant $[12,13]$. With the correct selection of varieties, schemes of their planting and formation, depending on the soil and climatic conditions, it is possible to predict in advance the possible quality of the future wine. In addition, it is well known $[14,15]$ that the use of green operations in vineyards can speed up or slow down the ripening of berries or the ripening of the vine.

Studying the relationship between the growing conditions of a grape plant and the predisposition of the finished wine to crystalline turbidities will help to identify a group of wines in the technology of which producers can use cheaper and simpler methods of preventing and eliminating turbidities, including crystalline ones.

\section{Materials and methods}

The objects of research were grape must from Cabernet-Sauvignon grapes grown in the

\footnotetext{
* Corresponding author: Khrapov.anton.al@gmail.com
} 
Anapa region (vines age - 5 years), as well as young wine materials obtained from it; formations of the grape plant Guyot and the two-armed Cordon. In the process of growing (late June - early July 2020), the grapes were subjected to green operations - chasing the upper leaves, removing stepsons, pinching. Grape must and wine materials were obtained using traditional grape processing technology. At the same time, the processing of grapes and the fermentation of the must were carried out under the same conditions: the fermentation temperature is $22-24{ }^{\circ} \mathrm{C}$, the yeast race of Oenoferm.

Physicochemical parameters of musts and wine materials were determined according to the methods of the current GOSTs.

The mass concentrations of organic acids and cations of alkaline and alkaline earth elements were determined by the author's methods using highly efficient capillary electrophoresis (Kapel 105, Kapel 105M "Lumex", Russia).

The salt content of the wine samples was determined by the conductometric method.

All tests were carried out three times.

\section{Results and discussion}

In Table 1 the results of the analysis of the mass concentration of sugars and titratable acids of grape must are presented.

Table 1. Physicochemical parameters of grape must

\begin{tabular}{|l|c|c|}
\hline \multirow{2}{*}{ Sample } & \multicolumn{2}{c|}{ Mass concentration } \\
\cline { 2 - 3 } & \multicolumn{1}{|c|}{$\begin{array}{c}\text { sugars, } \\
\mathrm{g} / 100 \mathrm{~cm}^{3}\end{array}$} & $\begin{array}{c}\text { titratable acids, } \\
\mathrm{g} / \mathrm{dm}^{3}\end{array}$ \\
\hline \multicolumn{3}{|c|}{ 1. Influence of shaping } \\
\hline Guyot & 22,8 & 5,7 \\
\hline Cordon & 21,0 & 7,6 \\
\hline \multicolumn{3}{|c|}{ 2. Influence of green operations } \\
\hline Control (Cordon) & 21,0 & 7,6 \\
\hline Chasing the upper leaves & 24,7 & 5,0 \\
\hline Pinching & 24,2 & 6,5 \\
\hline Removing stepsons & 23,9 & 6,1 \\
\hline
\end{tabular}

As can be seen from Table 1, the use of the Cordon shaping makes it possible to obtain must with a lower sugar content and a higher titratable acidity than with the Guyot shaping. At the same time, the use of any green operations aimed at improving the quality of the crop naturally leads to an increase in the sugar content and a decrease in titratable acidity.

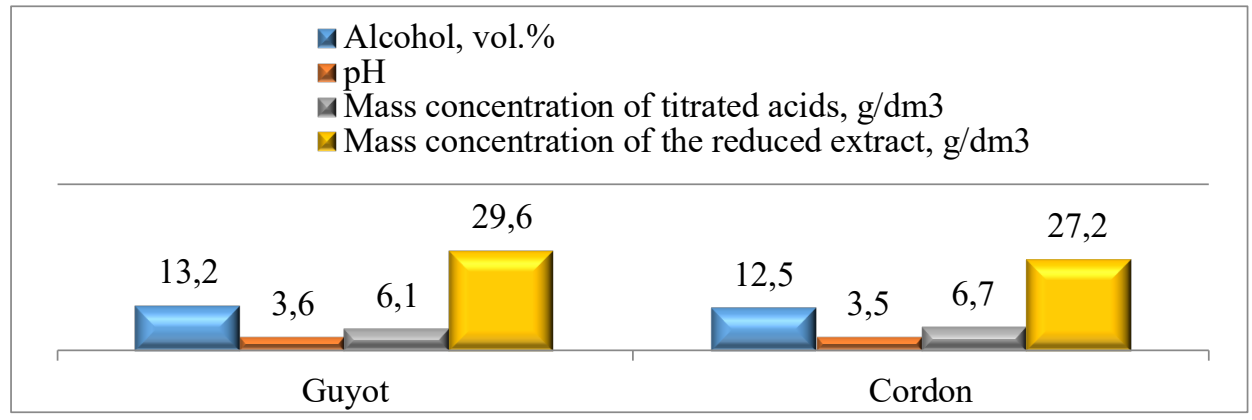

Fig. 1 The influence of the grape bush formation on the physicochemical parameters of wine materials 
Fig. 1 and Fig. 2 shows the results of the analysis of physical and chemical parameters of wine materials.

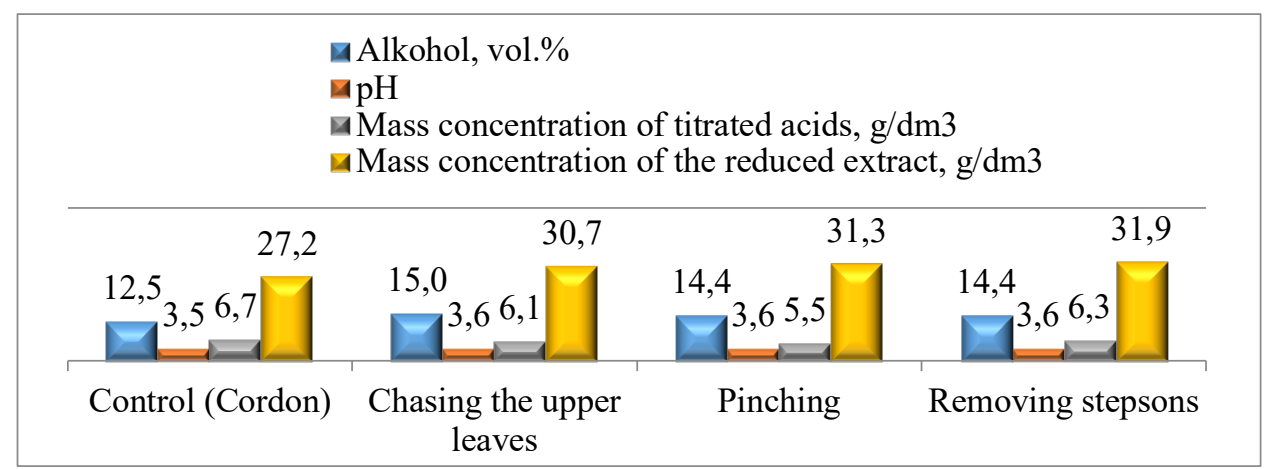

Fig. 2 The influence of green operations on the physicochemical parameters of wine materials

As seen from Fig. 1 and Fig. 2, the results of the analysis of physicochemical parameters of wine materials correlate with the parameters of must. Wine material from grapes grown using the Cordon formation is less extractive, the ethanol content in it is lower, the $\mathrm{pH}$ is lower, and the titratable acidity is higher, thus, we can say that with the use of the Guyot formation it is possible to obtain more complete taste and extractive wines than with using the Cordon shaping.

In turn, the use of green operations naturally leads to an increase in the content of ethanol and extractive substances in wine materials, while the $\mathrm{pH}$ value also increases and the titratable acidity decreases - wine materials are obtained more complete and saturated.

Table 2 shows the results of the analysis of the cations content in the samples of wine materials.

Table 2. Change in the concentration of metal cations depending on the formation of the grape bush and green operations

\begin{tabular}{|l|c|c|c|c|}
\hline \multirow{2}{*}{ Sample } & \multicolumn{4}{c|}{ Mass concentration of cations, $\mathrm{mg} / \mathrm{dm}^{3}$} \\
\cline { 2 - 5 } & $\mathrm{K}$ & $\mathrm{Na}$ & $\mathrm{Mg}$ & $\mathrm{Ca}$ \\
\hline \multicolumn{5}{|c|}{1. Influence of shaping } \\
\hline Guyot & 966 & 77,7 & 94,7 & 65,7 \\
\hline Cordon & 801 & 60,3 & 99,3 & 62,3 \\
\hline \multicolumn{5}{|c|}{ 2. Influence of green operations } \\
\hline Control (Cordon) & 801 & 60,3 & 99,3 & 62,3 \\
\hline Chasing the upper leaves & 1440 & 100,0 & 119,0 & 48,0 \\
\hline Pinching & 1470 & 97,1 & 127,0 & 69,9 \\
\hline Removing stepsons & 1100 & 89,1 & 117,0 & 54,9 \\
\hline
\end{tabular}

Analysis of the data in Table 2 shows that the type of formation and the use of green operations during the growth of a grape plant affect the content of cations of alkaline and alkaline earth elements in wine materials. It was found that the use of the Cordon formation leads to a decrease in the concentration of potassium and sodium cations in comparison with the Guyot formation. At the same time, the mass concentrations of magnesium and calcium underwent insignificant changes.

The use of green operations leads to a noticeable increase in the concentration of cations of alkali and alkaline earth metals, including potassium and calcium. 
The obtained values of the mass concentrations of potassium and calcium cations make it possible to predict the formation of crystalline turbidities in wine materials, which is also confirmed by the results of the analysis of the salinity of the samples, which, along with electrical conductivity, is one of the indicators of the stability of wine materials to crystalline turbidities. The results of the analysis of salinity are presented in Fig. 3 and Fig. 4.

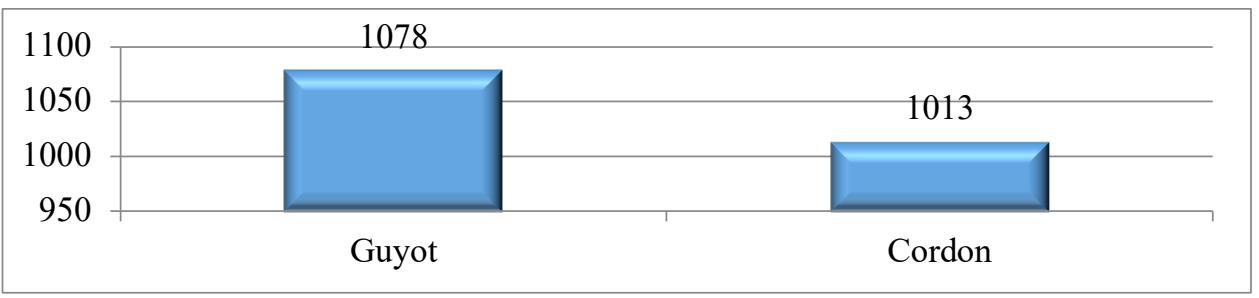

Fig. 3 Analysis of the salinity of wine samples depending on the formation of a grape bush, $\mathrm{mg} / \mathrm{dm}^{3}$

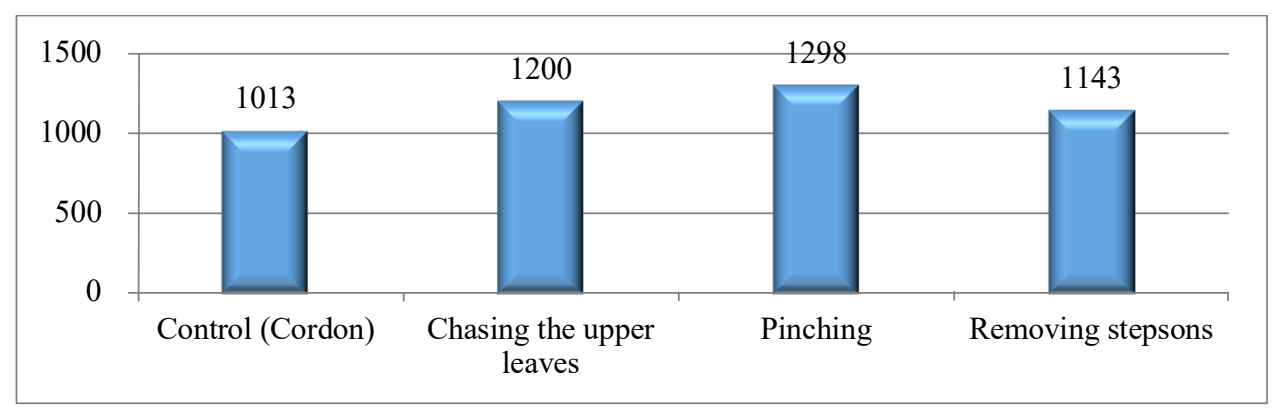

Fig. 4 Salinity analysis of wine samples depending on green operations, $\mathrm{mg} / \mathrm{dm}^{3}$

As seen from Fig. 3 and Fig. 4 - the values of the salt content indicator also depend on the applied shaping and green operations.

Potassium and calcium cations in grape wines actively interact with organic acids (counterions) to form salts - tartrates, bitartrates, malates, succinates, most of which form crystalline turbidities. In this regard, the change of the organic acids concentration in wine materials is interesting.

Table 3 presents the results of the analysis of the organic acids composition in samples of wine materials.

Table 3. Influence of shaping and green operations on the concentration of organic acids in wine materials

\begin{tabular}{|l|c|c|c|c|c|c|c|c|}
\hline \multirow{2}{*}{ Sample } & \multicolumn{7}{|c|}{ Mass concentration of organic acids, g/dm ${ }^{3}$} \\
\cline { 2 - 9 } & Tartaric & Malic & Succinic & Citric & Acetic & Lactic & $\begin{array}{c}\text { Total organic } \\
\text { acids }\end{array}$ \\
\hline \multicolumn{8}{|c|}{1 Influence of shaping } \\
\hline Guyot & 2,7 & 0,69 & 1,07 & 0,39 & 0,31 & 0,24 & 5,39 \\
\hline Cordon & 2,9 & 0,53 & 1,00 & 0,35 & 0,30 & 0,67 & 5,72 \\
\hline \multicolumn{8}{|c|}{2. Influence of green operations } \\
\hline Control (Cordon) & 2,9 & 0,53 & 1,00 & 0,35 & 0,30 & 0,67 & 5,72 \\
\hline Chasing the upper leaves & 1,7 & 1,88 & 1,05 & 0,36 & 0,17 & 0,21 & 5,33 \\
\hline Pinching & 1,7 & 1,51 & 1,27 & 0,48 & 0,25 & 0,36 & 5,58 \\
\hline Removing stepsons & 1,4 & 1,97 & 1,17 & 0,40 & 0,12 & 0,26 & 5,30 \\
\hline
\end{tabular}


As can be seen from Table 3, the use of the Cordon formation led to an increase in the concentration of tartaric acid $(\sim 7.5 \%)$ relative to the Guyot formation; the change in the concentrations of malic and lactic acids is associated with the incomplete course of malolactic fermentation. The concentrations of the remaining acids were similar.

The use of green operations aimed at improving the quality of grapes and wine led to a significant decrease in the concentration of tartaric acid $(\sim 40-50 \%)$ and a simultaneous increase in the accumulation of malic acid $(\sim 180-270 \%)$.

\section{Conclusion}

This paper presents the results of a study of the influence of the formation of a grape bush (Cordon or Guyot) of the Cabernet-Sauvignon variety, as well as green operations (chasing the upper leaves, pinching, removing stepsons) on the physicochemical characteristics of grape must and wine material produced from it, followed by an assessment of its stability to crystalline turbidities.

It has been shown that when using the Guyot formation, in comparison with the Cordon formation (as well as when using various green operations), it is possible to obtain more extractive wines, however, the accumulation of potassium and calcium cations increases and the content of tartaric acid decreases. In wine materials, the ratio of the concentrations of counterions is violated, which leads to uncontrolled formation of precipitation. The best of the green operations can be considered the removal of stepsons, in which the extract of wine materials significantly increases, and the salt content and concentrations of cations and organic acids remain at an acceptable level.

Acknowledgments. The research was carried out with the financial support of the Kuban Science Foundation in the framework of the Commercializable scientific and innovation projects competition № NIP-20.1/2.

\section{References}

1. J.A. Considine E. Frankish, In: A Complete Guide to Quality in Small-Scale Wine Making, 57-77 (Academic Press, 2014) https://doi.org/10.1016/B978-0-12-4080812.00005-6

2. C. Lasanta, J. Gómez, Trends Food Sci. Technol., 28, 52-59 (2012) https://doi.org/10.1016/j.tifs.2012.06.005

3. P.P. Lankhorst, B. Voogt, R. Tuinier, B. Lefol, P. Pellerin, C. Virone. J. Agric. Food Chem., 65, 265-272 (2017) https://doi.org/10.1021/acs.jafc.7b01854

4. L. Filipe-Ribeiro, J. Milheiro, R. Guise, R. Vilamarim, J.B. Fraga, C. Martins-Gomes, F.M. Nunes, F. Cosme, Food Chem., 360, 129996 (2021) https://doi.org/10.1016/j.foodchem.2021.129996

5. A. Bajul, V. Gerbaud, S. Teychene, A. Devatine, G. Bajul, J. Cryst. Gowth, 472, 54-63 (2017) https://doi.org/10.1016/j.jcrysgro.2017.03.024

6. R. Guise, L. Filipe-Ribeiro, D. Nascimento, O. Bessa, F.M. Nunes, F. Cosme, Food Chem., 156, 250-257 (2014) https://doi.org/10.1016/j.foodchem.2014.01.081

7. A. Bosso, S. Motta, M. Petrozziello, M. Guaita, A. Asproudi, L. Panero, Food Chem., 212, 821-827 (2016) https://doi.org/10.1016/j.foodchem.2016.06.044

8. C. Lasanta, I. Caro, L. Pérez, Food Chem., 138(2-3), 1072-1078 (2013) https://doi.org/10.1016/j.foodchem.2012.10.095

9. A. Calvo-López, E. Martinez-Bassedas, M. Puyol, J. Alonso-Chamarro, Food Chem., 345, 128779, (2021) https://doi.org/10.1016/j.foodchem.2020.128779 
10. R.S. Jackson, In: Wine Science (Fifth Edition), 573-723 (Academic Press, 2020) https://doi.org/10.1016/B978-0-12-816118-0.00008-8

11. A.M. Mislata, M. Puxeu, E. Nart, S. de Lamo, R. Ferrer-Gallego, LWT, 138, 110669 (2021) https://doi.org/10.1016/j.lwt.2020.110669

12. C. Grainger, A. Yeh, S. Byer, A. Hjelmeland, M.M. Lima, R.C. Runnebaum, Food Chem., 334, 127386 (2021) https://doi.org/10.1016/j.foodchem.2020.127386

13. M.M. Lima, D. Hernandez, A. Yeh, T. Reiter, R.C. Runnebaum, Food Res. Int., 141, 110045 (2021) https://doi.org/10.1016/j.foodres.2020.110045

14. N. Graveline, M. Grémont, Agric. Water Manag., 250, 106837 (2021) https://doi.org/10.1016/j.agwat.2021.106837

15. A.A. Crook, D. Zamora-Olivares, F. Bhinderwala, J. Woods, M. Winkler, S. Rivera, C.E. Shannon, H.R. Wagner, D.L. Zhuang, J.E. Lynch, N.R. Berryhill, R.C. Runnebaum, E.V. Anslyn, R. Powers, Food Chem., 354, 129531 (2021) https://doi.org/10.1016/j.foodchem.2021.129531 